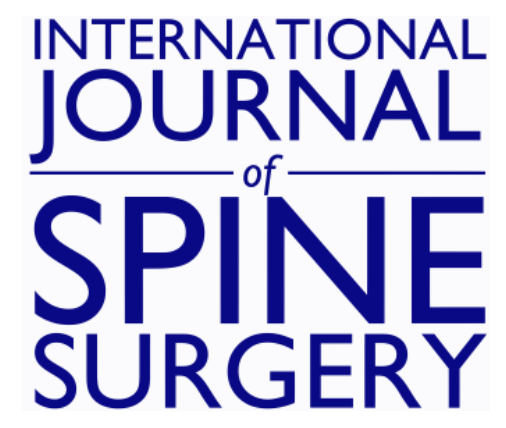

\title{
Nonoperative Management of a Multi-Regional Epidural Abscess with Neurological Dysfunction
}

Maire-Clare Killen, Miguel Hernandez, Andrew Berg and Chandra Bhatia

Int J Spine Surg 2015, 9 ()

doi: https://doi.org/10.14444/2047

http://ijssurgery.com/content/9/47

This information is current as of April 26, 2023.

Email Alerts Receive free email-alerts when new articles cite this article. Sign up at:

http://ijssurgery.com/alerts

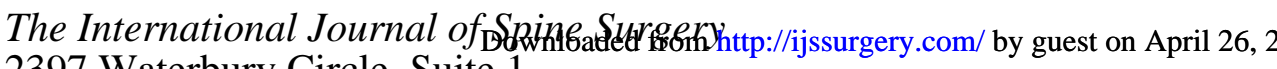
2397 Waterbury Circle, Suite 1,

Aurora, IL 60504, Phone: +1-630-375-1432

(C) 2015 ISASS. All Rights Reserved. 


\section{Nonoperative Management of a Multi-Regional Epidural Abscess with Neurological Dysfunction}

Maire-Clare Killen, MbChB, MRCS, ${ }^{1}$ Miguel Hernandez, MD, ${ }^{1}$ Andrew Berg, MMBS MRCS, ${ }^{2}$ Chandra Bhatia MS(orth), MChOrth ${ }^{1}$

${ }^{1}$ Spinal Unit, University Hospital of North Tees, Stockton-on-Tees, 2Pennine Acute NHS Trust

\section{Abstract}

Spinal epidural abscesses are uncommon, but their incidence is increasing. They represent a collection of purulent material in the epidural space and most commonly occur in the lumbar spine, where they remain localised.

Abscesses that affect all three spinal levels (holospinal or multiregional abscesses) are extremely rare, with only a few cases published in the literature.

Epidural abscesses are particularly high risk infections as progressive neurological dysfunction can occur rapidly; early diagnosis and treatment is therefore essential to avoid long term neurological complications and reduce potential mortality.

Given the uncommon nature of this condition, the treatment remains controversial with no definitive guidance on conservative versus surgical management. The literature mostly recommends surgical decompression along with intravenous antibiotics in patients with neurological abnormalities.

We describe a case of a 77-year-old patient presenting with a delayed diagnosis of a multi-regional epidural abscess with associated upper motor neurone signs. The patient was successfully treated nonoperatively with a course of antibiotics resulting in complete radiological resolution of the abscess and full neurological recovery.

KEYWORDS: EPIDURAL, ABSCESS, MULTI-REGIONAL, NONOPERATIVE

VOLUME 9 ARTICLE 47 DOI: 10.14444/2047

\section{Background}

Spinal epidural abscesses (SEA) are uncommon but potentially severe infections that require prompt recognition and definitive treatment in order to avoid significant neurological morbidity and even death.

Although uncommon, spinal abscesses, along with the incidence of spinal infections as a whole are increasing. Spontaneous epidural abscesses are thought to affect $0.2-2.8$ cases per 10,000 hospital admissions. ${ }^{1,2}$

SEA most commonly occur, and remain localised to the lumbar spine. Abscesses can affect any spinal level however, and one third of cases extend over more than six vertebral segments. ${ }^{3}$ Despite this, extensive multi-regional, or holospinal abscesses remain rare and pose a particular challenge when deciding on treatment options; both nonoperative and operative management of these patients has been described in the literature. We describe such a case of a 77-yearold patient who presented with a multi-regional epidural abscess and associated neurological deficit. She was successfully managed nonoperatively with a prolonged course of intravenous antibiotics.

\section{Case Presentation}

A 77-year old, otherwise well female patient presented to the accident and emergency (A\&E) department with a one week history of diffuse back and bilateral groin pain. She was reviewed and discharged with a course of oral antibiotics for a presumed urinary tract infection.

Worsening symptoms and systemic upset prompted further presentation to $\mathrm{A} \& \mathrm{E}$ four days later, where she was found to have raised inflammatory markers (White cell count, WCC $13.8 \times 10^{9} / \mathrm{L}$ and C-reactive protein, CRP 276mg/L). At this time she was admitted for further investigation and treatment of possible pyelonephritis. The patient was commenced on 
intravenous tazocin for treatment of a suspected urinary source of infection.

Ultrasound of the urinary tract did not reveal any abnormalities and urine cultures were negative. Due to the ongoing back pain and persistently elevated inflammatory markers, MRI of the lumbar spine was performed. This revealed extensive, multi-level degenerative disc disease. More significantly, an extradural cystic mass was visualised extending anteriorly from T10 to L1, raising the suspicion of epidural abscess (Figure 1).

The results of blood cultures taken on admission grew penicillin-resistant, but flucloxacillin-sensitive Staphylococcus aureus. Antibiotics were changed to intravenous flucloxacillin and oral fusidic acid on the advice of the consultant microbiologist.

At this time, the patient had a limited neurological examination documented by the medical team with normal motor power and globally intact sensation.

The patient was reviewed by a spinal fellow 48 hours following admission. A further, more detailed history was taken, where the patient described difficulty walking in the six-weeks preceding admission. Neurological examination at this time found globally reduced power (MRC grade 4/5) in all muscle groups of the lower limbs with normal power in both upper limbs; widespread hyperreflexia in both upper and lower limbs with up-going plantar reflexes was evident. Due to these findings the patient underwent urgent MRI of the whole spine and was transferred to

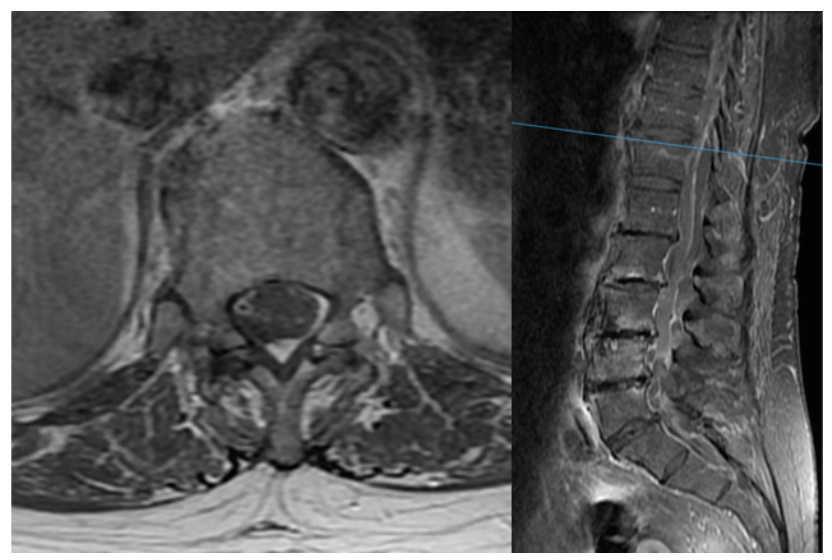

Fig. 1. Initial lumbar MRI scan demonstrating extradural cystic collection extending to L1. the spinal ward for further treatment. Due to acute renal impairment, a non-contrast MRI scan was performed.

Subsequent cervical and thoracic MRI showed an extensive epidural abscess, extending proximally from $\mathrm{C} 2$ down to $\mathrm{T} 9$ anterior to the cord and from $\mathrm{C} 2$ to T11 posterior to the cord (Figure 2).

After four days of intravenous antibiotics, inflammatory markers were improving (WCC $12.2 \times 10^{9} / \mathrm{L}$, CRP $146 \mathrm{mg} / \mathrm{L}$ ) and there was no further decline in neurology, so the decision was made to continue with nonoperative management.

The patient continued on dual-antibiotics over the next 14-days. At this time, the patients' neurological status was gradually improving. Her mobility had improved and she could walk without feeling unstable and power in the lower limbs had returned to normal (MRC grade 5/5 in all muscle groups).

After four weeks of intravenous antibiotics the inflammatory markers had markedly improved (WCC 7.4, CRP 26). The patient underwent repeat MRI scan of the whole spine, which showed complete resolution of the extensive cervical and thoracic abscess, with a small persisting collection at T11 (Figure 3).

The patient had no persisting neurological deficit and was discharged with oral flucloxacillin for a further 5 weeks. Blood results following the completion of the course of antibiotics demonstrated normal inflammatory markers (WCC 6.4, CRP $<1$, ESR

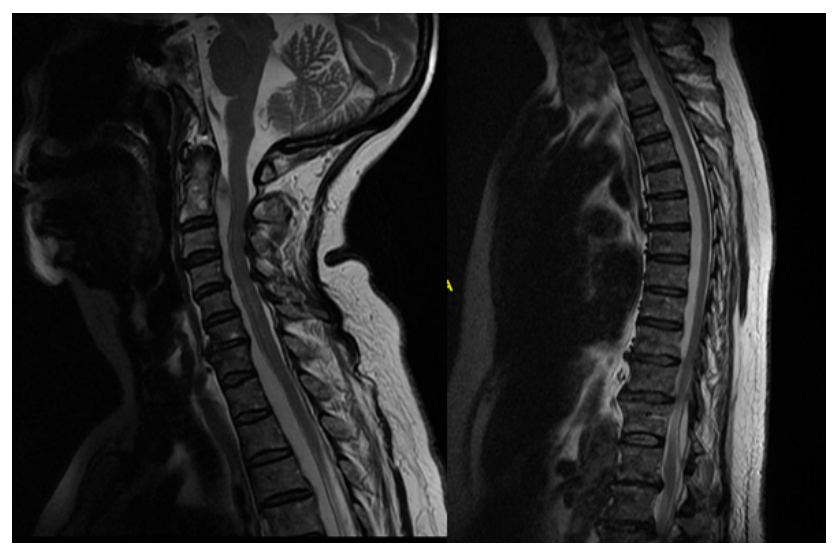

Fig. 2. Additional T2-weighted images of the cervical and thoracic spine showing a widespread epidural collection. 
$13 \mathrm{~mm} / \mathrm{hr}$ ). Repeat MRI scan 12 months following presentation showed complete resolution of all infective features (Figure 4).

\section{Discussion}

SEA is a rare condition first described in the literature in 1761 by Morgagni and involves a collection affecting the epidural space in the spinal canal. ${ }^{4} \mathrm{Al}-$ though rare, with an estimated incidence of 0.2-2 cases per 10,000 hospital admissions, this incidence of SEA increasing ${ }^{1}$ and it is estimated to have almost doubled in the last decade. This increase is thought to be due to several factors, including increasing age of the population, rising intravenous drug use and an increase in the number of invasive spinal procedures. ${ }^{5-8}$

Despite this increase, the number of multi-regional spinal abscesses reported in the literature remains small.

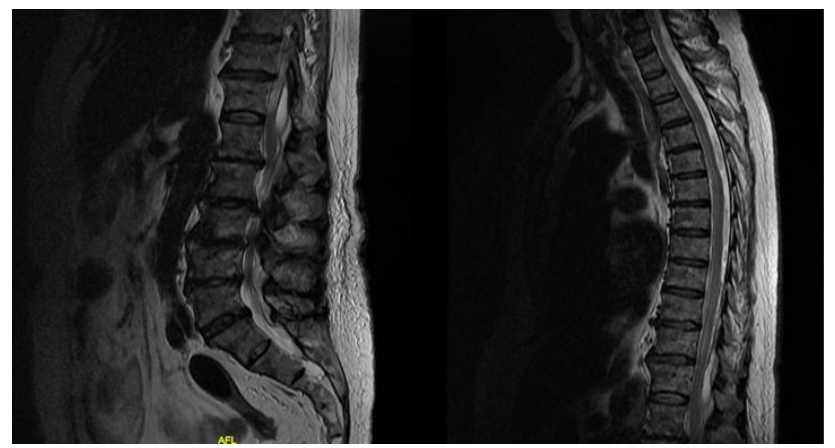

Fig. 3. After 4 weeks of antibiotics, repeat MRI showed improving findings, with a small persisting collection at T11.

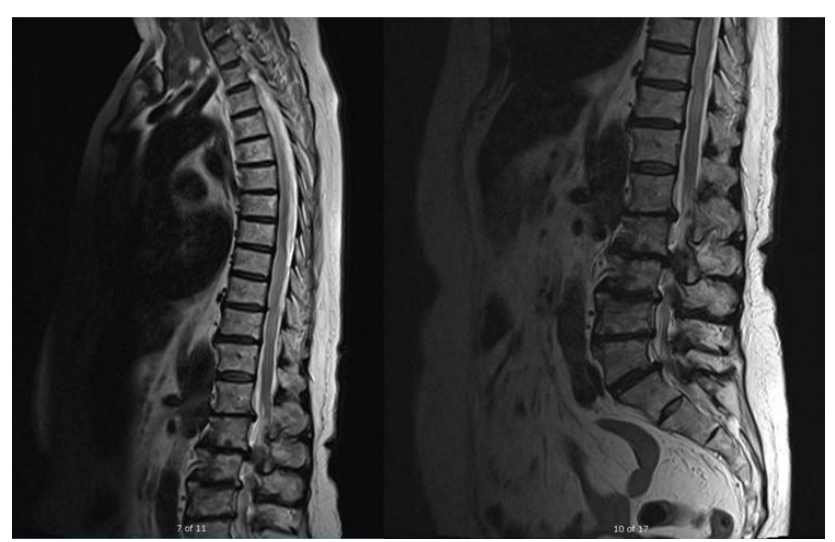

Fig. 4. Further MRI at 12 months from initial presentation, with complete resolution of radiological findings.
SEA can affect patients of any age group, and large case series have shown a male to female ratio of $2: 1 .^{9}$ Although some cases occur in patients with no predisposing factors, epidural abscesses occur more commonly in those with co-morbidities. Individuals with any cause for immunocompromise, including diabetes mellitus, human immunodeficiency virus, intravenous drug use, chronic renal disease, malignancy and long term steroid use are at increased risk of developing SEA in comparison to the general population. ${ }^{10}$

The development of an epidural abscess can occur by several mechanisms. In approximately $50 \%$ of cases the cause is haematogeneous seeding.

Iatrogenic inoculation from either invasive spinal procedures, diagnostic or therapeutic percutaneous injections can result in the formation of an abscess. Finally, contiguous spread can lead to extension and formation of SEA, most often from an adjacent vertebral body osteomyelitis or discitis. ${ }^{5,11,12}$

Early recognition and treatment is the most important determinant in reducing the associated neurological morbidity and potential mortality.

Patients with SEA usually present with back pain, symptoms of systemic upset, with or without accompanying neurological symptoms. Physical examination will often reveal spinal tenderness to palpation and pyrexia. Neurological deficit, if present, can be extremely variable, ranging from radiculopathy to paraplegia or quadriplegia..$^{13-15}$

As in our case, patients with SEA often first present to the accident and emergency department; it is therefore important for clinicians to have a high index of suspicion in this patient group in order to appropriately investigate and instigate treatment as quickly as possible.

Blood parameters will show raised inflammatory markers. CRP and ESR are perhaps the most helpful markers and are more often raised in cases of SEA compared to white cell count. ${ }^{15}$ Blood cultures are positive in up to $60 \%$ of cases; the identification of the infecting organism is important in order to tailor 
antimicrobial therapy. ${ }^{16-18}$ Patients should also be investigated for a possible primary source of bacteraemia. By far the most common infecting organism is Staphylococcus aureus, being isolated in up to $70 \%$ of cases; this is followed by Streptococcus in 7\%. Although uncommon overall, gram negative bacilli are often seen in intravenous drug users. ${ }^{9,19}$

Gadolinium-enhanced magnetic resonance imaging of the whole spine is the investigation of choice for diagnosis and determining the extent and location of the abscess. ${ }^{8,20,21}$

Even with a rising incidence of SEA, there is currently no clear consensus regarding treatment; the use of nonoperative versus surgical management remains widely debated. Early reviews strongly favoured surgical evacuation in all patients with epidural abscesses. However, a recent systematic review has shown an increasing number of patients being managed nonoperatively when presenting with back pain in the absence of neurology, compared to previously published literature, with no statistically significant difference in outcomes between those in the different treatment groups. ${ }^{22}$

Primary nonoperative treatment with antibiotics has been described in the literature. ${ }^{3,22}$ Several factors to favour medical management have been identified, including patients over 50 years old or with significant co-morbidities; the absence of neurology, or conversely, neurological dysfunction that has been persistent for more than 36 hours. As in our case, extensive multi-regional SEA has also been described as an indication for conservative management. ${ }^{22,23}$

Strong indications for emergency surgery include clinical or neurological deterioration despite intravenous antibiotic therapy targeted to the infecting organism, spinal instability or progressive deformity. The aims of surgical intervention are to reduce and eradicate the infective load, decompression and preservation spinal stability. ${ }^{24}$

Patient outcomes have markedly improved in recent years, with improved awareness and better diagnostic tools to allow early recognition and treatment. However, there is still a significant associated morbidity and mortality. This is largely dependent on patient factors; poorer outcomes are seen in patients with overt sepsis at the time of presentation as well as significant immunocompromise or multiple comorbidities. Infection with methicillin resistant staphylococci species is also linked with poor prognosis. $^{25,26}$

Neurological prognosis is also variable. Important factors in neurological outcomes include the severity of dysfunction at the time of presentation and the duration between onset of neurological symptoms and commencement of treatment. ${ }^{27,28}$

Despite the increasing incidence of spinal epidural abscesses, multiregional abscesses continue to be a rare problem with very few cases reported in the literature. Treatment remains debated and different authors have described successful treatment with both operative and nonoperative management, depending on patient factors and presenting symptoms.

This case emphasises the importance of early clinical recognition of patients exhibiting signs and symptoms of SEA as well as early treatment with antibiotics. Despite the presence of neurological dysfunction, which has previously been described as an indication for surgery, we have demonstrated that widespread multiregional epidural abscesses can be successfully treated nonoperatively with antibiotics, provided there is early clinical improvement. Complete resolution of neurology and radiological findings occurred in this case with antibiotics alone.

\section{References}

1. Fang WK, Chen SH, Huang DW, Huang KC (2009) Post-traumatic osteomyelitis with spinal epidural abscess of cervical spine in a young man with no predisposing factor. J Chin Med Assoc 72:210-213.

2. Mackenzie AR, Laing RB, Smith CC, Kaar GF, Smith FW (1998) Spinal epidural abscess: the importance of early diagnosis and treatment. J Neurol Neurosurg Psychiatry 65:209-212.

3. Manickam A, Marshman L, Korah I (2014) Panregional (cervico-thoraco-lumbo-sacral) spinal 
epidural abscess with multi-level discitis, vertebral body osteomyelitis and facet joint septic arthritis: complete resolution with nonoperative management. Interdisciplin neurosurg 1: 69-72.

4. Morgagni JB: The Seats and Causes of Diseases Investigated by Anatomy; in Five Books, Containing a Great Variety of Dissections, With Remarks. To Which Are Added Very Accurate and Copious Indexes of the Principal Things and Names Therein Contained. Alexander B, trans. London: Johnson and Payne, 1769.

5. Darouiche RO: Spinal epidural abscess (2006) N Engl J Med 355: 2012-2020.

6. Nussbaum ES, Rigamonti D, Standiford $\mathrm{H}, \mathrm{Nu}-$ maguchi Y, Wolf AL, Robinson WL (1992) Spinal epidural abscess: a report of 40 cases and review. Surg Neurol 38:225-231.

7. Pereira CE, Lynch JC (2005) Spinal epidural abscess: an analysis of 24 cases. Surg Neurol 63 (Suppl 1):S26-S29.

8. Rigamonti D, Liem L, Sampath P, Knoller N, Namaguchi Y, Schreibman DL, et al (1999) Spinal epidural abscess: contemporary trends in etiology, evaluation, and management. Surg Neurol 52:189-197.

9. Reihsaus E, Waldbaur H, Seeling W (2000) Spinal epidural abscess: a meta-analysis of 915 patients. Neurosurg Rev 23:175-205.

10. Zimmerer S, Conen A, Muller A et al (2011) Spinal epidural abscess: aetiology, predisponent factors and clinical outcomes in a 4-year prospective study. Eur Spine J 20:2228-2234.

11. Reynolds F (2008): Neurological infections after neuraxial anesthesia. Anesthesiol Clin 26:23-52.

12. Sendi P, Bregenzer T, Zimmerli W (2008) Spinal epidural abscess in clinical practice. QJM 101:1-12.

13. Deardrechao, Anil nanda (2002) Spinal Epidural Abscess: A Diagnostic Challenge. Am Fam Physician 65(7):1341-1347.

14. Pradilla G, Ardila GP, Hsu W, Rigamonti D (2009) Epidural abscesses of the CNS Lancet Neurol 8(3):292-300.

15. Tompkins M, Panuncialman I, Lucas P, Palumbo M (2010) Spinal Epidural Abscess. J Emerg Med 39(3): 384-390

16. Danner RL, Hartman BJ (1987) Update of spinal epidural abscess: 35 cases and review of the literature. Rev Infect Dis 9:265-74.

17. Davis DP, Wold RM, Patel RJ, et al (2004) The clinical presentation and impact of diagnostic delays on emergency department patients with spinal epidural abscess. J Emerg Med 26:285-91.

18. Curry WT, Hoh BL, Amin-Hanjani S, Eskandar EN (2005) Spinal epidural abscess: clinical presentation, management, and outcome. Surg Neurol 63:364 $-71$.

19. Klekamp J, Samii M. Extradural infections of the spine (1999) Spinal Cord 37:103-9.

20. Hlavin ML, Kaminski HJ, Ross JS, Ganz E (1990) Spinal epidural abscess: a ten-year perspective. Neurosurgery 27:177-84.

21. Modic MT, Feiglin DH, Piraino DW, et al (1985) Vertebral osteomyelitis: assessment using MR. Radiology 157:157- 66.

22. Arko L, Quach BS, Nguyen V et al (2014) Medical and surgical management of spinal epidural abscess: a systematic review. Neurosurg Focus 37(2): $1-9$.

23. Tuchman A, Pham M, Hsieh P (2014) The indications and timing for operative management of spinal epidural abscess. Neurosurg focus 37(2): 1-8. 24. Smith G, Cochar A, Manjila S et al (2014) Holospinal epidural abscess of the spinal axis: two illustrative cases with review of treatment strategies and surgical techniques. Neurosurg Focus 37: 1-8. 25. Kim SD, Melikian R, Ju KL, Zurakowski D, Wood KB, Bono CM, et al (2013): Independent predictors of failure of nonoperative management of spinal epidural abscesses. Spine J 30:1606-1609. 26. Patel AR, Alton TB, Bransford RJ, Lee MJ, Bellabarba CB, Chapman JR (2014) Spinal epidural abscesses: risk factors, medical versus surgical management, a retrospective review of 128 cases. Spine J 14:326-330.

27. Heusner AP (1948). Non-tuberculous spinal epidural infection. N Engl J Med 239:845-54. 28. Kumar K, Hunter G (2005). Spinal epidural abscess. Neurocrit Care 2:245-51.

\section{Disclosures}

There was no actual or potential conflict of interest in relation to this submission between authors and no financial sponsorship was received for this article. 
No benefits in any form have been received or will be received from a commercial party related directly or indirectly to the subject of this article.

\section{Corresponding Author}

Maire-Clare Killen, Spinal Unit, University Hospital of North Tees, Stockton-on-Tees. maire- clare.killen@doctors.org.uk.

Published 17 September 2015.

This manuscript is generously published free of charge by ISASS, the International Society for the Advancement of Spine Surgery. Copyright $\odot 2015$ ISASS. To see more or order reprints or permissions, see http://ijssurgery.com. 